\title{
Etnonimlerde "Ew" (> Ewi, Ewli) Bileşeni ve Alkaewli, Karaewli Adlarının Esası Üzerine ${ }^{1}$
}

\author{
About the Component of "Ew" (>Ewi, Ewli) in Ethnonym Ctructures and the \\ Ogininals of Alkaewli, Karaewli Tribe Names
}

\author{
İbrahim Şahin \\ Doç. Dr., Ege Üniversitesi \\ Türk Dünyası Araştırmaları Enstitüsü, İzmir / Türkiye \\ e-posta ibrahim.sahin@ege.edu.tr \\ orcid 0000-0002-0167-2568 \\ doi $\quad 10.54316 /$ dilarastirmalari.997926
}

Atıf

Citation

Şahin, Ibrahim (2021). Etnonimlerde "Ew" (> Ewi, Ewli) Bileşeni ve Alkaewli, Karaewli Adlarının Esası Üzerine.

Dil Araştırmaları, 29: 43-53.

Başvuru
Submitted
20.09.2021
Revizyon
Revised
01.11.2021
Kabul
Accepted
03.11.2021
Çevrimiçi Yayın
Published Online
30.11.2021

\section{Başvuru}

Submitted

Revizyon

Revised

Kabul

Accepted

Çevrimiçi Yayın

30.11.2021

\begin{abstract}
öz
Alkaewli ve Karaewli boyları tarihi kaynaklarda çok farklı imlalarla anılmaktadır. $\mathrm{Bu}$ boyların tarih sahnesindeki izlerini konu edinen araştırmalarda, söz konusu kökadlarının (etnonimlerin) yapısına ve anlamına yönelik, bu çerçevede "ewli" bileşeninin (component) yapısı üzerine, bazı yüzeysel değerlendirmeler yapılmışsa da bunda başarılı olduğu söylenemez. $\mathrm{Bu}$ değerlendirmelerde Karaewli ve Alkaewli etnonimlerindeki bu yapının (“ewli”), 'ev' sözcüğüyle ilgili olduğu değerlendirilmiş; Karaewli etnoniminin 'evi, çadırı kara olan' anlamına geldiği ileri sürülmüştür. $\mathrm{Bu}$ makalede konu, "ewi” "ewli/ewlü” bileşeniyle kurulu çok sayıda toponim örneğinden hareketle ele alınmış ve Musul'un Telafer ilçesi silikyeradlarından (mikrotoponimleri) elde edilen bulgular temelinde açıklanmıştır. Telafer silikyeradları (mikrotoponimleri) üzerine derlemeye dayalı yaptığımız bir çalışması sırasında, "ewi" yapısının toponimlerde sıkça görüldüğü fark edilmiş ve bölge halkı tarafından bu bileşenin '... boyu, ....aşireti' anlamında kullanıldığ 1 tespit edilmiştir: Ör. Aloewi 'Alo Aşireti', Efendiewi 'Efendi Aşireti'. Bu bilgi, "ewi”, "ewli” yapılı etnonimlerin anlam çözümlemesinde anahtar rol oynamıştır. Söz konusu bulgu, bu yapıdaki toponimlerin esasen etnotoponim (kökadlıyeradları) olduklarını ortaya çıkarması bakımından da önemli olmuştur. Buna göre, makaleye konu olan kökadlarının esasen Alka ve Kara oldukları; kalıplaşmış bir görüntü içerisinde bulunan "ewli" bileşeninin ise, '... aşiretine/boyuna/topluluğuna mensup olan’ anlamına gelen kökadcıl bir
\end{abstract}

\footnotetext{
${ }^{1}$ Bu makale, 22-24 Nisan 2021 tarihlerinde düzenlenen I. Uluslararası Adbilim Sempozyumu'da, Etnonimlerde "Ew" (> Ewi, Ewli) Bileşeni ve Oğuzlarin Alkaewli, Karaewli Boy Adlarinin Esası, adıyla sunulan bildirinin genişletilmişş şeklidir.
} 
belirteç (ethnoyimic indikator) olduğu sonucuna varılmıştır.

Anahtar Kelimeler: kökad1, Alkaewli, Karaewli, ew bileşeni, kökadcıl belirteç

\section{ABSTRACT}

The Alkaewli and Karaewli tribes are mentioned with quite different spellings in historical sources. In the studies on the traces of these tribes on the stage of history, some superficial evaluations have been made on the structure and meaning of the aforementioned ethnonyms and on the structure of the "ewli" component in this context, but it cannot be said that this has been succesful. In these evaluations, it has been evaluated that this structure ("ewli") in the ethnonyms Karaewli and Alkaewli is related to the word "house"; it has been suggested that the ethnonym Karaewli means "the one whose house is black, the one whose tent is black'. In this article, the subject is discussed by considering many toponym examples established with the "ewi" "ewli/ewlü" component and explained on the basis of the findings obtained from the microtoponyms of the Tal Afar district of Mosul. During a compilation study on Tal Afar microtoponyms, it was noticed that the "ewi" structure is frequently seen in toponyms and it was determined that this component was used in the sense of " $\ldots$ clan, ... tribe" by the people of the region: Ex. Aloewi 'Alo Tribe', Efendiewi 'Efendi Tribe'. This information has played a key role in the meaning analysis of "ewi", "ewli" structured ethnonyms. The aforementioned finding was also important in terms of revealing that toponyms in this structure are essentially ethnotoponyms. Accordingly, the ethnotoponyms that are the subject of the article are mainly Alka and Kara; it has been concluded that the "ewli" component in a stereotyped image is an ethnoyimic indicator meaning "members of the tribe/ clan/ community".

Keywords: ethnonym, Alkaewli, Karaewli, component of "ew", ethnoymic indikator

\section{Giriş}

Onimler (özel ad) bir gelenek içerisinde doğarlar. Bu sebeple, onların ortaya çıkış1 konusundaki bir bilgiyi tespit etmek, o dilin farklı zamanlarında, farklı coğrafyalarında vücut bulmuş aynı tipteki başka adların da çözümü anlamına gelir. Buna bağlı olarak, günümüzde unutulmuş görünen, ancak hayatın başka bir alanında halen varlığını sürdüren, özel adların (onim) şekillenmesiyle ilgili gelenek bilgilerinin ortaya çıkarılması adbilim sahasının en önde gelen görev ve amaçlarındandır. Özel adların bir türü olan kökadları (etnonimler) ${ }^{2}$ da bunun dışında değildir.

$\mathrm{Bu}$ makalede, bazı kökadı (etnonim) yapılarında geçen, ancak anlam ve görevi araştırmacılarca belirlenememiş olan "ewli, öylü, üylü, oylu, ivli" bileşeni (kompanent) üzerine durulacaktır. Daha önce müstakil bir araştırmaya konu olmamış

\footnotetext{
${ }^{2}$ Makalede, adbilim ve onun alt kollarına ait bazı terimler kullanılmaktadır. Bu terimlerin imla ve çerçevesinde, İbrahim Şahin, Adbilim, Pegem Akademi Yayınları, 2015 kitabı esas alınmıştır.
} 
bu meseleye, Irak Türklerinden (özelde Telafer) tespit ettiğimiz bir bulgudan yola çıkılarak açıklama getirilecektir.

Söz konusu bileşen (kompanent), meşhur 24 Oğuz boyundan Alkaewli ve Karaewli adlandırmalarında bulunduğu gibi, esasen daha az ya da hiç meşhur olmayan kökadlarında ve bunlarla kurulu kökadliyeradlarında (etnotoponimlerde) da görülmektedir: Örneğin, Osmanlı yeradları (toponimleri) arasında geçen Dervişevli k. (Yörükan-1 Naldöken), Karacaevli (Yörükan-1 Vize), Koyunevli (Yörükan-1 Naldöken), Oruçevli (Tataran-1 Aktav), Ağaevli (İshaklı kz., Akşehir 1.), Kalınevli (Onikidivan kz., Bolu 1.), gibi yerleşim adlarında da bu bileşenin olduğu kanaatindeyiz. (Örnekler için bk. Osmanlı Yer Adları Sözlüğü (OYS) I/II.) Yine 40-50 yıl öncesine kadar göçer hayat yaşayan, şimdilerde Taşeli platosunun çeşitli kısımlarına (Anamur, Bozyazı, Mut) yerleşmiş bulunan ve aşiret bilincini halen belirli ölçüde saklayan Keşevli (halk arasında Keşefli olarak da söylenir) aşiretinin adında da bu bileşenin bulunduğunu düşünüyoruz. Tarihî ve çağdaş yeradları (toponimler) arasından daha fazla örnek bulmak mümkünse de; verilen örneklerin yeterli olduğunu düşünerek meseleyi, söz konusu iki meşhur Oğuz boyunun adı üzerinden tartışmanın uygun olacağı kanaatindeyiz. Öncelikle bu boy adlarının tarihi kaynaklardaki görünümünü ve bu tarihi kaynaklar üzerine çalışan modern tarihçilerin söz konusu boy adlarını ne şekilde okuduklarını ve varsa bu adların yapılarına ilişkin görüşlerini vermek yerinde olacaktır:

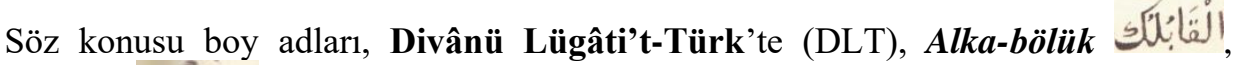
Kara-bölük

Reşideddin'in Oğuznâmesinde de anılan bu boy adları, Z. V. Togan tarafindan Alkavlı Avul ve Kara Avul biçimlerinde okunmuştur. Eserde birincisi için "vardığı her yerde başarı ve refaha mazhar olan", ikincisi için "kara yolda iyi giderdi" anlamları verilmiştir (Togan 1982: 51). F. Sümer, Reşideddin’ de söz konusu boyların القر أو لى ve ve biçiminde kaydedildiğini gösterir ve bunları Alkaravl ve Kara-ivli (Reşideddin'de geçen yazım esasen "Kara-ivi" şeklinde okumaya müsaittir. Sümer burada, diğer kaynaklardaki genel imlayı ve okuyuşu dikkate aldığı anlaşılıyor.) şeklinde okur. Eserde, Alkaravlı adının "Nereye varsa başarı gösterir.", Kara-ivli adının ise, "kara otağlı" anlamıyla geçtiği kayıtlıdır (Sümer 1999: 230).

Tevârîh-i Âl-i Selçuk'ta (A Nüshası)

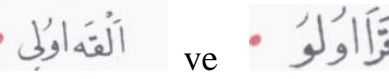
biçimlerinde kaydedilmiştir (Yazıcıoğlu 2014: 3a). A nüshasındaki yazımları Alkä̈vli ve Karä̈vlü; B nüshasındaki yazımları Alkaevli/Karaevlü ve $T$ nüshasındaki yazımları Alkaevli/Karaevli biçimlerinde okumuş olup söz konusu eserde, birincisinin her yere yararlar, muvafakat iderler"; ikincisinin "evleri kara" anlamına geldiği kayıtlıdır (bk. Bakir 2017: 6n, 20n).

Şecere-i Terâkime'de ise, Alka-ivli ve Kara-ivli (T1,T2,T3'te Alka-öyli ve Karaöyli) biçimlerinde anılır. Birincisinin "muvafik", ikincisinin ise "her kayda oltursa hargâh birlen olturguçı” anlamına geldiği kayıtlıdır (Ebulgazi Bahadır Han 1996: 153, 159). 
Buradaki bilgiler topluca değerlendirildiğinde, kökadlarının birleşik yapıya sahip oldukları anlaşılmaktadır. Ayrıca ilkinin birinci bileşeninin 'başaran, muvafik' anlamına gelen alka (ya da alkar); sonrakinin ise, 'siyah' anlamına gelen kara sözcüğü olduğu anlaşılmaktadır. Sorun her iki etnonimin ikinci bileşenindedir. ${ }^{3}$ Zira eserlerdeki imlaları ve buna bağlı olarak okumaları bir birinden farklıdır. Bu bileşeni, 'köy' anlamına gelecek şekilde "avul" biçiminde transkribe eden Togan'ın okumasını ayrı tutarsak (ki kanaatimizce bu bileşen "avul" değildir), söz konusu bileşen anılan kaynaklarda "bölük”, “avlı”, “ivli”, “ivi”, “övlü”, “övli”" “öyli” gibi farklı şekillerde geçmektedir (diğer bir deyişle okumaya müsaittir).

$\mathrm{Bu}$ boyların tarih sahnesindeki izlerini konu edinen tarih araştırmalarında, söz konusu bileşenin anlamıyla ilgili bazı yüzeysel değerlendirmeler yapılmışsa da, bildiğimiz kadarıyla, ayrıntılı bir araştırmaya konu olmamıştır. F. Sümer, yukarıda bahsi geçen metinlerde, Alkaewli ve Karaewli kökadlarının tarihi kaynaklarda ne şekilde yazıldığınıi göstermiş, DLT'teki biçimlerinden hareketle söz konusu adların ilk kısmının "Alka" ve "Kara"; farklı şekillerde okunan ikinci kısımların ise, "evli" olduğunun açık olduğunu ifade etmiş ve sözcüğü 'ev/çadır' anlamına gelen "ev" sözcügü ile ilişkilendirmiştir (Sümer 1999: 254). Sonraki çalışmalarda, bu görüşün tekrar edildiği görülmektedir.

Biz, bu bileşenin Telafer Türkmenlerinden derlediğimiz bir bilgiden hareketle izah edilebileceğini düşünüyoruz. Danışmanlığı tarafımızca yürütülen "Telafer ilçesi Mikrotoponimleri ve Dil İncelemesi” isimli yüksek lisans tez çalışması sırasında, Telafer ve köylerinden derlediğimiz malzemeler arasında Aloewi, Efendiewi gibi yeradları bulunmaktaydı. Alo ve Efendi, bölgede günümüzde de bilinen aşiret adları olup söz konusu aşiretlerin yerleştiği yerlere bu isimler verilmişti. Adlandırmaların kuruluşunda görev yapan ewi ise Musul'da, Karakoyun ve Telafer Türkleri arasında 'aşiret' anlamına gelmekteydi. Dolayısıyla Alo-ewi 'Alo Aşireti'; Efendi-ewi 'Efendi Aşireti' anlamlarına geliyordu (ayrıntılı bilgi için bk. Barem 2018). Biz, Telafer'de, Aloewi ve Efendiewi yeradlarının yapısında görev alan ewi bileşeni ile yukarıda, tarihî kaynaklarda farklı imlalarla anılan, buna bağlı olarak farklı şekillerde okunan bileşenin aynı sözcük olduğunu değerlendirdik.

Buna göre söz konusu bileşenin kökü "ew"dir, anacak bu sözcük "ev, çadır" anlamında bir sözcük değildir. Etnonimlerde ewli $[<$ ew+li] ya da ewi $[<$ ew + i] yapılarında görülen bu sözcüğün ilk şekli (yani ewli), 'falanca aşiretine/boyuna/tayfasina mensup', 'falanca aşiretinden/boyundan/tayfasindan olan(lar)' anlamını ifade ederken ikinci biçim (yani ewi), 'falanca aşireti/boyu/uşağı̆, $v b$. ' anlamını ifade etmektedir. Bu çıkarım, bize adı geçen boy adlarının gerçekte, Alka ve Kara olduklarını söyleme imkânı verdiği gibi, yine bu boyların diğer tarihi kaynaklardan farklı olarak niçin DLT'te Alkabölük ve Karabölük şeklinde geçtiğini de anlamamıza yardımcı olmaktadır: Elde edilen bu bilgiler burada ele aldığımız etnonimlerin kuruluşlarında geçen gerek "ewi/ewli" ve gerekse "bölük" bileşenlerinin kökadcıl belirteç (indikator) olduğunu ve aynı işlevde kullanıldığını açıkça ortaya

\footnotetext{
${ }^{3}$ Elbette ilk kökadının birinci bileşeninin alka mı yoksa alkar mı olduğu da bir sorundur. Ancak bu makalenin odak noktası her iki kökadının ikinci bileşeni üzerine yoğunlaştığından, bu meseleye değinilmeyecektir. $\mathrm{Bu}$ daha başka müstakil bir çalışmanın konusu olabilir.
} 
koymaktadır. Diğer bir ifadeyle, aynı görevde (kökadcıl belirteç) kullanılan bu leksik birimler, yukarıdaki tarihi eserlerde alternans bir kullanım içerisindedirler. Bu tespitten hareketle, "bölük" ve "ewi/ewli" bileşeni, göreceli olarak daha geç etnonim yapılarında karşılaştı̆̆ımız “...ulusu, ...uşă̆l, ...aşireti, ...oğulları, ...obası” gibi kökadcıl belirteçlerden ya da bunların eklerle ifade edildiği $\{+1 \mathrm{I}\},\{+1 \mathrm{IcA}\},\{+\mathrm{cA}\}$, $\{+\mathrm{cAlI}\}$ morfemlerinden görev ve anlamca hiç de farklı değillerdir.

Burada önemli bir hususun altını çizmeliyiz: Söz konusu etononimlerin DLT’de "bölük”, diğerlerinde "ewi /ewli" (ve farklı varyantları) bileşeniyle kullanılmış olması, gerek "bölük" ve gerekse "ewi/ewli" bileşenlerinin Alka/Alkar ve Kara isimli boy adlarıyla tam olarak kalıplaşmadığını göstermesi bakımından önemlidir. $\mathrm{Bu}$ durum boyadlarının geçmişte halk arasında, tarihçiler arasında yalın biçimleriyle (Alka/Alkar, Kara) ya da "bölük", "ewi/ewli" bileşenleriyle benzer işlevde kullanılan farklı bir kökadcıl belirteçle de (leksik ya da morfolojik) kullanılmış olabileceğini düşündürmektedir: Burada anlattıklarımıza, Orta Toroslar'da halen aşiret bilincini yitirmemiş bir aşiretin halk arasındaki farklı adlandırma şekillerinden örnek verebiliriz.

Yoğun olarak 60'lı yıllarda yerleşik hayata geçmiş olan ancak halen tek tük de olsa konargöçer mensupları bulunan Bahşiş/Bahşış/Baaşış aşireti, günümüzde bölge halkının dilinde bazen tek başına "Bahşış/Bahşiş/Baaşış/Bağşış" olarak anılırken bazen de "Bahşış/Baaşış Aşireti", "Bahşış-obası" ya da kökadcıl ek getirilmek suretiyle; "Bahşışlar/Baaşışlar", "Bahşışl1/Baaşışlı", gibi çok farklı şekillerde anılmaktadırlar. Bu durum, Alkaewli boy adının farklı kaynaklarda (örneğin toponimler, etnonimler gibi), yukarıda zikredilen bilinen kullanımları dışında Alka-uşă̆ı, Alka-obası, Alkalı, Alkalar, Alkaca, Alkacalar, Alkacall, Alkacalılar; Karewli boy adının da yukarıda zikredilen kullanımları dışında Kara-ulus(u), Kara-obası, Kara-uşă̆l, Kara, Karalar, Karalılar, Karalıca, Karacall, Karacalılar, Karacı, Karacılar gibi farklı koşutlarla da kullanılmış olabileceğini düşünmeyi gerektirir. Nitekim, Oğuz boy isimleriyle Türkiye yeradlarında, çok sayıda yerleşim adına rastlanırken (94 adet Kayı, 86 adet Afşar, 81 adet Kınık, vs.), "Kara-Evli" boyuna ait 8, "Alka-Evli” boyuna ait ise hiçbir yerleşim adının tespit edilememiş olmasının (Sümer 1999: 408, 427) bir açıklaması olmalıdır. Nitekim, F. Sümer, isabetli bir görüşle, çağdaş Türkiye toponimisinde bugün hâlâ varlığını koruyan Halka-Evli, Halka-Avlu, Halka-Havlu köy adlarının "Alka-Ewli" boyu ile ilgili olduğunu ve hatta Halkalı adındaki birçok köy adının da bu boy adıyla ilişkili olabileceğini dile getirmiştir (1999: 255), ki biz de Sümer'le aynı kanaati paylaşıyoruz.

Gerek Sümer'in ileri sürdüğü görüş ve gerekse söz konusu kökadlarının yalın biçimlerinin Alka ve Kara olduğu fikrinden hareketle, Osmanlı tahrirlerinde geçen aşağıdaki yeradlarını bu boy adlarıyla ilişkilendirmenin mümkün olacağını düşünüyoruz:

\section{ALKA Boyu İle İlgili Olması Muhtemel Etnotoponimler (Kökadlıyeradları)}

1.1. Anadolu, Karaman, Rum, Diyarbakır, Arap ve Zülkadriye Eyaletlerindekiler 
Halka, (Tarsus kz.'da karye); Halkaavlu (Ruha kz.'da mezra); Halkabükü (Boyabad kz.'da karye); Halkabünüş (Konya kz.'da mescit); Halkaçayır (Tokat kz.'da mezra); Halkaçayırı (Kırşehri kz.'da mezra); Halkaçayırı (Bozok kz.'da mezra); Halkaevli (Kedeğra kz.'da karye); Halkahavlu (Eskişehir kz.'da karye); Halkahavlu (Daday kz.'da karye); Halkahavlu (Ilgun kz.'da karye); Halkahavlu (Kelkid kz.'da karye); Halkahavlu (Murtazabad kz.'da karye); Halkahavlu (Yenişehir kz.'da karye); Halkahavlu (Aksaray kz.'da karye); Halka-i Has (Zile kz.'da nahiye); Halka-i Hass (Zile kz.'da kale); Halkakolu (Çerkeş kz.'da karye); Halkaköy (Tarsus kz.'da mezra); Halkalar (Karahisar kz.'da mezra); Halkalar (Haleb kz.' da nahiye); Halkalı (Kürtün kz.'karye); Halkalukuyu (Aksaray kz.'da mezra); Halkalukuyu (Koçhisar kz.'mezra); Halkapınar asiyabı, (İzmir kz.'da çarşı); Halkapınar (İzmir kz.'da zaviye); Halkapınar/Gücbey (Şuhud kz.'da karye). Örnekler için bk. OYS-II 2013: 595).

\subsection{Rumeli Eyaleti'ndekiler}

Halka (Yörükan-1 Vize'de karye); Halka/Halkalı/Halkalar (Yörükan-1 Naldöken'de karye); Halkadis (?) (Narda kz.'da karye); Halkaköy (Yörükan-1 Naldöken'da karye); Halkaköy (Yörükan-1 Tanrıdağı'da karye); Halkalar (Yörükan-1 Selanik'te karye); Halkalar (Yörükan-ı Tanrıdağı' da karye); Halkalı (Yörükan-1 Tanrıdağı'nda karye); Halkapınarı (Filibe kz.'da karye); Halkapınarı (Hasha-i İstanbul kz.' da karye). Örnekler için bk. OYS-I 2013: 330).

Naldöken Yörüklerinin yayıldığı sahada bulunan ve defterlerde adı Halka/Halkalı/Halkalar gibi farklı şekillerde tespit edilmiş olan karye (köy) adı, yukarıdaki değerlendirmemizi, yani aynı kökadının farklı kökadcıl belirteçlerle kullanılabileceği görüşümüzü, desteklemesi bakımından dikkate değerdir.

Alka-ewli boy adının hem birinci hem de ikinci bileşeninin kelime başı / $\mathrm{h} /$ protezi aldığı görülüyor ki, kelime başı /h/ türemesi olayı genel Türk dilinde ve Anadolu ağızlarında sık rastlanan (ayva $>$ hayva; imdi $>$ hindi; o $>$ ho, ora $>$ hora) bir durumdur: "Alka"nın "halka"ya, "ewli"nin havlu”ya dönüşümünde yaşanan kelime başı /h/ türemesi olayını, kanaatimizce anolojik bir yaklaşım (“alka" ve "ewli” sözcüklerinin anlamlarının unutulmuş olması ve bu sözcüklere ses değeri bakımından çok benzeyen "halka" ve "havlu" sözcüklerinin herkesçe biliniyor oluşu) tetiklemiş olmalıdır. Söz konusu kökadları özelinde, bu ses olayının (Alka > Halka) gerek Anadolu ve gerekse Rumeli yeradlarındaki istikrarlı durumu göz önüne alındığında, kökadındaki bu değişimin, etnonim taşıyıcılarının Anadolu'ya gelmeden önceki bir dönemde yaşandığı; dolayısıyla Osmanlı tarih yazıcılarının bu yeni biçimi tanıdıkları ve kullandıkları söylenebilir.

\section{KARA Boyu İle İlgili Olması Muhtemel Etnotoponimler (Kökadlıyeradları)}

Yukarıda, Kara-ewli kökadının farklı kökadcıl belirteçlerle de karşımıza çıkabileceğinden söz etmiş (tıpkı DLT'te "Kara-bölük” örneğinde olduğu gibi); farklı kaynaklarda (örneğin toponimlerde) Kara-ulus(u), Kara-obası, Kara-uşăğ, Karalar, Karalılar, Karalıca, Karacalı, Karacalılar gibi koşutlarla da aranması gerektiğinden söz etmiştik. Ancak hemen ifade etmek gerekir ki, Kara etnonimi Alka etnonimi kadar 
ayırt edici bir niteliğe sahip değildir. Zira "kara" sözcüğü toponimlerde gayet işlek bir kullanıma sahip olup (tıpkı Ak, Kızıl, Sarı gibi) tek bir kaynağı işaret etmezler. Kimi zaman coğrafi bir objenin rengini ifade ederken kimi zaman bir şahsın adında lakap olarak kullanılabilir. Bunlara ek olarak, Kara-Kıtay, Kara-Kıpçak, Kara-Mangıt, KaraTürgeş, Kara-Yıvalu, vb. örneklerde görüleceği üzere (örnekleri için Bkz. LezinaSuperanskaya 2009: 310-330) çeşitli boy adlarının üzerine gelerek tamladığı boy adının bir şubesini de ifade edebilir. Tüm bunlar, düzenli olarak sıfat tamlaması yapısında kullanılmış olsalardı, bugünün araştırmacıları için bir sorun teşkil etmeyebilirdi; ancak sıfat tamlaması yapısındaki etnonimlerin (ör. Kara-Kıtay, KaraKıpçak, vs.), dilde ekonomi prensibi çerçevesinde, tamlanan unsurun düşmesiyle (ör. Kara-Kıpçak > Karalar gibi) Kara, Karalı, Karalar, Karaca, Karacı, Karacalar şeklinde bir adlaşmış sıfat yapısına dönüşebilmesi, araştırmacıyı işin içinden çıkılmaz bir manzara ile karşı karşıya bırakmaktadır. Zira, geçmişte toplumun aşiret, oymak, boy çerçevesinde yapılandığ 1 ve bu çerçevede insanlarda şecere bilgisinin güçlü olduğu çağlarda "Karalar"1n hangi boy olduğu bilinirken (ör. Kara-Kıpçak mı, Kara-Kıtay mı, vs.) günümüz araştırmacılarının bunu, yerleşim adlarından hareketle tespit etmesi çok mümkün değildir. Özetle yerleşim adlarında karşımıza çıkan Karalı, Karalar, ... gibi adların boy adından geldiğini söylemek mümkün olsa da bunların Kara-Kıpçaklar mı, Kara-Kıtaylar mı; yoksa "kara" sıfatını taşıyan daha başka bir boydan mı kısalarak (adlaşmış sıfata dönüşerek) geliştiğini belirlemek oldukça güçtür. Hatta örneğin bir coğrafyada Kara-Kıtay adı, Karalar, Karalı, vs. şeklinde kısalırken farklı bir zaman ve coğrafyada Kara-Kıpçak adının da aynı dil olgusu çerçevesinde kısalarak Karalar, Karall, vs. biçimlerine dönüşmesi; hatta bunların Anadolu'ya göç etmesiyle aynı isim altında yeradları oluşturmaları teorik olarak mümkündür.

Burada demek istediklerimizin daha iyi anlaşılabilmesi için Sarı/Sarıl1/Sarılar, vs. adındaki boy adını örnek verebiliriz. Türk halklarının etnogenezi üzerine çalışan K. Şaniyazov, R. Kuzeyev, V. V. Bartold, E. N. Necef, B. E. Kumekov, vb. birçok bilim insanı tarihi kaynaklarda Sarı /Şarı, olarak anılan halkın Kıpçaklar olduğunu, Orta Çağ kaynaklarında Hardeş, Koman, Plovki, Valanı adlarıyla geçen halkların da aynı halk olup tüm bunların 'Sarılar' demek olduğunu, yine Şarı, Kula adlarının da aynı anlama geldiğini dile getirmektedirler (Şaniyazov 1974: 29, 30; Kumekov 2013: 128-135). Şaniyazov, X-XII. Yüzyıl kaynaklarında Kıpçakların Ak-Kıpçaklar, Kara-Kıpçaklar ve Sarı-Kıpçaklar adıyla üç gruba ayrıldığını, Sarı etnoniminin Sarı-Kıpçak adından kısalma yoluyla meydana geldiğini ifade etmiştir (Şaniyazov 1974: 30). Sarı boyu etrafındaki tartışmalar ve bu boyun Türkiye'deki izleri üzerine geniş bilgi için bkz. Şahin 2016.

Bütün bunlara bağlı olarak Kara (ewli) etnonimiyle ilgili olabileceğini düşündüğümüz aşağıdaki toponimler bu gözle (ihtiyatla) değerlendirilmelidir.

\subsection{Anadolu, Karaman, Rum, Diyarbakır, Arap ve Zülkadriye Eyaletlerindekiler}

Karaevli (Gerede kz.'da karye); Karaevli (Kastamonu kz.'da karye); Karaevli (Tokat kz.'da karye); Karaevli (Onikidivan kz.'da karye); Karaevli (Turhal kz.'da karye);

Kara(ewli) boy adından geldiği gayet açık olan bu toponimler dışında aşağıda sıralanan toponimlerin de söz konusu boyla ilişkili olmaları muhtemeldir. 
Karalar (Bergama kz.'da karye); Karalar (Çimenili kz.'da karye); Karalar (Çubuk kz.'da karye); Karalar (Kastamonu kz.'da karye); Karalar (Homa kz.'da karye); Karalar (İnegöl kz.'da karye); Karalar (Eskişehir kz.'da karye); Karalar (Kerkük kz.'da karye); Karalar (Kütahya kz.' da karye); Karalar (Murtazabad kz.'da karye); Karalar (Sandıklı kz.'da karye); Karalar (Canik-i Bayram kz.'da karye); Karalar (Selendi kz.'da karye); Karalar (Sifrihisar kz.'da karye); Karalar (Amasya kz.'da karye); Karalar (Kocakayası kz.'da karye); Karalar (Karahisar-1 Demürlü kz.'da mezra); Karalar (Beyşehri kz.'da mezra); Karalar (Koçhisar kz.'da mezra); Karalar (Karahisar-1 Şarki kz.'da mezra); Karalar (Malatya kz.'da mezra); Karalar nehri (Kınık kz.'da); Karalar yolu (Şam livasında); Karalar/Dumanlı (Ilgun kz.'da karye); Karalar/Eberiler (Balıkesri kz.'da karye); Karalarköyü sınırı (Selendi kz.'da); Karalı (Tokat kz.'da karye); Karalı (Bozok livasında mezra); Karaluca (Kürtün kz.'da mezra); Karaluderesi (Sis kz.'da mezra); (Örnekleri için bkz. OYA II, 2013: 765, 777).

\subsection{Rumeli Eyaletindekiler}

Karaevli (Çorlu kz.'da karye); Karaevli (Müselleman-1 Çingane'de karye); Karaevli (Müselleman-1 Vize'de karye); Karaevli (Tekfurdağı kz.'da karye); Karaevli (Yörükan-1 Vize'de karye); Karalar (Fenar kz.'da karye); Karalar (Paşa livasında karye); Karalar (Şumnu kz.'da karye); Karalar (Tatarbazarı kz.'da karye); Karalar (Yörükan-1 Kocacık'ta karye); Karalar (Yörükan-1 Naldöken'de karye); Karalar (Yörükan-1 Ofçabolu'da karye); Karalar (Yörükan-1 Selanik'te karye); Karalar/Altunlar (Yenişehir kz.'da karye); Karalı-yı Küçük (Yörükan-1 Vize'de karye); (OYS-I 2013: 432,437, 438,439,440,442 )

Yukarıdakiler dışında, "Kara", "Karaca", "Karacalı/Karacalu", "Karacalar", "Karacı", Karacılar" şeklindeki mezra ve köy adlarının (bkz. OYA I, 2013: 432, 437, 439; OYA II: 743, 744, 751, 756) da büyük bölümünün Kara şeklindeki bir etnonimden geliştiğini söyleyebiliriz. Bununla birlikte onların Kara(ewli) boy adından geldiklerini kesin bir dille söylemek ne yazık ki mümkün değildir. Zira yukarıda da ifade edildiği üzere bunlardan bazılarının "kara" tamlayııı unsurunu taşıyan başka boy, oymak, aşiret adından (ör. Kara-Kıtay, Kara-Yıvalu, Kara-Bahşili, vs.) kısalarak (adlaşmış sıfat yapısında) aynı adda buluşma ihtimalini göz ardı edemeyiz.

\section{Ewi / Ewli Sözcügünün Anlamı}

Anadolu etnotoponimerinde (kökadlıyeradlarında) görülen "ewli”, "ewi” sözcüğü, her ne kadar günümüzde Türkiye Türkleri arasında unutulmuş görünse de Irak'taki Telafer Türkmenleri arasında, "ewi" şeklinde bir sözcüğün etnonim yapılarında görev yaptığını ve bunun '... aşireti' anlamına geldiğini yukarıda ifade etmiştik. 3. Tekil iyelik eki olduğu açık olan sondaki eki kaldırdığımızda, yalın biçim olan "ew" ögesinin 'aşiret, boy, kabile, vs.' şeklinde etnik birliği ifade eden bir sözcük olduğu ortaya çıkmaktadır. Tarihî kaynaklara bu biçim ve anlamda tek başına kullanılan leksik bir birime (sözcüğe) rastlamıyor olsak da, bunun Dîvânü Lügâti't-Türk'te (DLT) "ay ewi" ('ay halesi') tamlamasında geçen (DLT I: 377) "ew" ile ilgili olduğunu düşünüyoruz. 'Işı̆̆ın etkisiyle Ay'ın çevresinde oluşan halka; 'hâle' anlamına geldiği anlaşılan bu ad 
soylu sözcük, yine DLT'te 'bir şeyin etrafinı çevirmek, kuşatmak' anlamına gelen $\boldsymbol{e w}$ eylemiyle (DLT I:167) de ilişkili olmalıdır. Bize göre DLT'te ad olan " $\mathrm{ew}$ " ile eylem olan ew- sözcükleri, Türkiye dilciliğinde "ikili kök", "eş sesli isim", "fïil-isim" gibi farklı terimlerle adlandırılan (terim için bk. Turan 1998: 246n) hem ad hem eylem soylu sözcük örneklerinden (Ör. göç/göç-, şiş/şiş-, geç/geç-, dik/dik-, karı/karl'ihtiyarla-', düz/düz-, don/don-, vs.) biridir. Sözcüğün eylem anlamında görülen 'bir şeyin etrafina koşuşmak' (yani halkalamak, çevrelemek) anlamı, sözcüğün ad biçimi olan 'hâle' (yani bir şeyi çevreleyen halka, yuvarlak) anlamında ortaya çıkmaktadır.

Kaşgarlı'nın bu sözcükten gelişen ewlen- sözcüğü için verdiği '1. hâlelenmek; 2. ev sahibi olmak' anlamları (DLT: 259) söz konusu sözcügün 'hâne, konut' anlamına gelen $e w$ sözcüğü ile de etimolojik yakınlık içinde olabileceğini düşündürmektedir. Buradan hareketle, kökeni etimologlar arasında tartışmalı olan (bk Eren 1999: s.141) 'hane, konak' anlamındaki "ev" sözcügü ile (Karahanlı Türkçesinde ew; Orhun Türkçesinde $e b$ ) evin aile bireylerini bir araya toplama, onları çevreleyen bir mekân olma özelliği dikkate alınarak söz konusu ew- ('bir şeyin etrafını çevirmek, kuşatmak') eylemiyle ilişkilendirmek ve 'hâne' anlamına gelen "ev" sözcüğü ile söz konusu fiilismi (ew/ew-) aynı köke bağlamak mümkün olabilir. Günümüzde yaygın kullanılan evril- ('bir tarafa yönelmek'), evirip çevir- ('yönetmek, çevirmek; alt üst etmek') eylemlerinin kökünde bulunan evir- eyleminin [(Atabetü'l-Hakayık'ta ewir- 'evirmek, çevirmek' (Edib Ahmed 1992: 74); DLT'de ewür- 'çevirmek, evirmek' (DLT I: 178); Orhun Türkçesinde ebir- '1. ülkeyi yönetmek, çekip çevirmek, 2. çevirmek, dolanmak'(BK D 25)] ew- kökünden, bu kökün de $e b$ - şeklinde daha eski biçimden geldiği açıktır: evir- < ewir- < eb- 'çevir-' + \{-ir\} 'faktitif eki'). DLT'te "kişi ewleşdi" ('halk toplandı, yığıldı') cümlesinde (DLT I: 240) geçen ewleş- sözcüğü de açık biçimde göstermektedir ki, yukarıda bahsi geçen ve 'hâle' anlamında kayda geçen ew sözcüğünün 'bir şeyi çevreleyen halka, top', buradan 'yığın, grup, topluluk' anlamı bulunmaktadır. İşte bu anlam, Irak Türklerinin dilinde 'aşiret, kabile' anlamında yaşayan "ew" sözcüğünü köken ve anlam açısından izah eder niteliktedir. Bu durumda Halka-ewli ve Kara-ewli boy adlarının kuruluşunda görülen "evli/ewlü”, yukarıda ifade edildiği biçimde, aralarında etimolojik bir yakınlık bulunsa da, 'hâne, konut' anlamına gelen $e w$ sözcüğüyle değil; 'topluluk, yığın, grup' anlamına geldiği anlaşılan "ew" sözcüğüyle ilişkilendirmek yerinde olacaktır. Tarihi kaynaklarda söz konusu kökadcıl belirtecin (ewli) aynı zamanda niçin "ewli, öylü, üylü, ivli, vb.” şekillerde kaydedildiğinin açıklaması da, "ew" sözcüğünün Türkçenin tarihi gelişimi içerisinde, lehçe ve ağızlarda aldığı farklı şekillerle (sözcüğün aldığı farklı şekiller için bk. Cevortyan 1974: 513-315) izah edilebilir.

\section{Sonuç}

Çağdaş ve tarihî etnonim kuruluşlarında çok farklı fonetik biçimlerle kaydedilen ve buna bağlı olarak “öylü, üylü, ewli, avlı, avlu, awul, ivi, ivli”, vb. biçimlerde okunmuş olan bileşen esasen kökadcıl bir belirteçtir (etnonimical indikatör). Bu kökadcıl belirteç, Irak Türkleri arasında halen varlığını koruyan 'aşiret' anlamına gelen "ew”, sözcüğüdür. Etnonim kuruluşlarında, "ewi" ve "ewli" biçimlerinde rastlanmaktadır. Birincisi (yani ewi), 'falanca aşireti', ikincisi ("ewli”) ise, 'falanca aşiretine 
mensup' anlamını bildirir. Özetle, kökadcıl belirteçlerden biri olduğu anlaşılan bu sözcük, benzer anlam ve görevde kullanılan "aşireti”, "boyu”, "ulusu”, "uşağı", "obası", "oğulları", gibi leksik unsurlar ile yine etnonimlerde aynı işlevde kullanılan "IAr", "II", "CA", "IIcA", "CAlI", vb. morfemlerle benzer anlam ve işleve sahiptir. Bu da, adı geçen boy adlarının esasen Alka ve Kara olduklarını ortaya koymaktadır. "Ewi", "ewli" bileşeniyle şekillenmiş etnonimleri araştırırken bunların indikatörsüz ya da başka indikatörlerle var olabileceği göz ardı edilmemelidir.

\section{Tartışma}

Seslik bir değişimle "Halka" biçimini alan Alka boyunu, Osmanlı yeradlarında "Halkaköy", "Halkalı", "Halkalar", "Halkalu”, "Halkahavlu”, vb. şekillerde tespit edebilmek mümkünse de, Kara (ewli) boy adıyla oluşan toponimlerin tespiti o kadar da kolay değildir. Esasen, söz konusu Kara boyunun burada konu edilen kökadcıl belirteçle kullanımını (yani Karaewli biçimini), yeradları içerisinde tespitte tereddüt yoktur. Sorun bu kökadının sade (yani Kara) ve başka kökadcıl belirteçlerle olan muhtemel kullanımlarında (ör. Karalı, Karacı, Karacılar, Karalar, Karalılar; Kara Obası, Kara Ulus, vs.) yaşanmaktadır. Zira "kara” sıfatı başka kökadı kuruluşlarında da kullanılan bir öge olduğundan, bu belirsizlik içerisinde Osmanlı toponimlerinde başta "Karalar", "Karalı", "Karacalar” olmak üzere "Kara/Karaköy”, "Karaca/Karacaköy”, "Karacı", "Karacılar", "Karacalar”, gibi yeradlarının hangilerinin bu makalede konu edilen Kara (yani Karaewli) boyu ile ilgili olduğunu güvenle söyleyebilmek oldukça güçtür ve çözümü de çok mümkün görünmemektedir. Bir diğer çözülmesi gereken önemli konu ise şudur: Tarihi kaynaklarda "bölük" ve "ewli” indikatörü ile karşımıza çıkan ve "Oğuz boyu" olduğu ifade edilen bu Kara boyu/aşireti kimdir? "KaraOğuzlar" adında bildiğimiz bir kökadı bulunamadığına göre, acaba hangi kökadının (Kara-Kıpçak, Kara-Kıtay, Kara-Tatar veya daha başka...) kısalmış şeklidir?

\section{Kaynakça}

BAREM, Ghadeer Mohammed Qasım (2018), Telafer Mikrotoponimleri ve Dil Incelemesi (Danışman: Doç. Dr. İbrahim Şahin), Yayınlanmamış Yüksek Lisans Tezi, İzmir: Ege Üni. Sosyal Bilimler Enstitüsü.

DLT: KÂş̧GARLI MAHMUd (2006), Divanü Lûgat-it-Türk I-IV. (Çev. Besim Atalay), Ankara: TDK.

EdiB AHMEd B. MAHMUd YÜKNEKî (1992), Atebetü'l-Hakayık (Yay. Hazırlayan Reşid Rahmetî Arat), Ankara: TTK.

EREN, Hasan (1999), Türk Dilinin Etimolojik Sözlüğü, Ankara: Bizim Büro.

Ebulgazi BaHAdir Han (1996), Şecere-i Terâkime, Türkmenlerin Soykütü̆̆ü, (Yay. Haz: Zuhal Karg1 Ölmez), Ankara: Simurg.

KAŞGARLi MAHMUd (1990), Dîvânü Lûgati 't-Türk, (Tipkıbasım), Ankara: Kültür Bakanlığı.

KumeKov, Bolot E. (2013), Arap Kaynaklarına Göre IX-XI. Asırlarda Kimek Devleti (Çev. Mehmet Kıldıroğlu, Çingiz Samudinuulu), Ankara: TTK.

LezinA, L. N. ve SuPERANSKAYA A. V. (2009), Türk Onomastikası -Bütün Türk Halkları-, İstanbul: Selenge.

OYA: OSMANLI YeR AdLARI SÖZLÜĞÜ I/II (2013), Yay. Haz. Ahmet Özkılınç, Ali Coşkun, vd., Akara: Başbakanlık Osmanlı Arşivleri.

Sevortyan, E. V. (1974), Etimologiçeskiy Slovar' Tyürkskih Yazıkov, Moskova: İsdatel'stvo "Nauka". 
Etnonimlerde "Ew" (> Ewi, Ewli) Bileşeni ve Alkaewli, Karaewli Adlarının Esası ... | 53

SüMER, Faruk (1999), Oğuzlar (Türkmenler) Tarihleri-Boy Teşkilatı-Destanları, İstanbul: Türk Dünyası Araştırmaları Vakfı.

ŞAHIN, İbrahim (2016), "Saruhan ve Saruhanoğulları Adlarının Kökeni Üzerine", Dil Araştırmaları, 2016/18, ss. 219-233.

ŞANiYAZov, K. (1974). K Etniçeskoy İstorii Uzbekskogo Naroda, Toşkent: İzdatel' stvo "Fan” Uzbekskoy SSR.

Togan, Zeki Velidi (1982), Oğuz Destanı, Reşideddin Oğuznâmesi, Tercüme ve Tahlili, İstanbul: Enderun Kitabevi.

TuRAN, Fikret (1998), "Modern Türkçede Fiil Tabanlarıyla Sesteş İsim Soylular ve Bir Terim Teklifi: Fiil-İsimler”, İlmi Araştırmalar, sayı 6.

YAZICIZÂDE Alî (2014), Selcuk-Nâme İndeksli Tipkıbasım (Yay. Haz. Abdullah Bakır), Ankara: TTK.

YAZICIZÂde Alî (2017), Tevârîh-i Âl-i Selçuk -Oğuznâne-Selçuklu Tarihi- (Yay. Haz: Abdullah Bakır), İstanbul: Çamlıca. 